Research Article

\title{
Physical and Mechanical Performance of Frozen Rocks and Soil in Different Regions
}

\author{
Junhao Chen $\mathbb{D}^{1,2}$ Lexiao Wang, ${ }^{2}$ and Zhaoming Yao ${ }^{1,3}$ \\ ${ }^{1}$ Key Laboratory of Underground Engineering, Fujian Province University, Fuzhou 350118, China \\ ${ }^{2}$ School of Civil Engineering, Fujian University of Technology, Fuzhou 350118, China \\ ${ }^{3}$ School of Civil Engineering and Architecture, Anhui University of Science and Technology, Huainan 232001, China \\ Correspondence should be addressed to Junhao Chen; chjhtougao@163.com
}

Received 4 August 2020; Revised 3 September 2020; Accepted 23 October 2020; Published 9 November 2020

Academic Editor: Yanjun Shen

Copyright ( 92020 Junhao Chen et al. This is an open access article distributed under the Creative Commons Attribution License, which permits unrestricted use, distribution, and reproduction in any medium, provided the original work is properly cited.

The artificial freezing method is extensively used in the reinforcement of engineering strata in various regions for shaft excavation and subway connection channels. In this study, representative rock and soil strata from different regions were subjected to lowtemperature physical and mechanical performance tests. The results show that, compared with Cretaceous and Jurassic rock and soil strata, deep topsoil and shallow coastal topsoil have high water content, low thermal conductivities, high frost heave rates, and high freezing temperatures. In addition, the results show that, as the curing temperature decreases, the uniaxial compressive strengths and elastic moduli of deep topsoil and shallow coastal topsoil increase almost linearly. The strength of the sandy soil strata is the highest, followed by the cohesive soil strata, and the strength of the mucky soil and the calcareous clay is the lowest. The strength of the frozen wall and the waterproof requirements must both be taken into account in the freezing design. Deep Cretaceous and Jurassic rocks can have high strength of more than $5 \mathrm{MPa}$ under normal temperature conditions. An increase in the uniaxial compressive strength and elastic modulus with decreasing curing temperature is mainly manifested within the range from the normal temperature to $-10^{\circ} \mathrm{C}$. The strength can reach more than $10 \mathrm{MPa}$ at $-10^{\circ} \mathrm{C}$, and only the strength requirements of the frozen wall need to be considered in the freezing design. At low temperatures, deep topsoil and shallow coastal topsoil are dominated by the form of compression failure. The average failure strain at $-10^{\circ} \mathrm{C}$ is typically greater than $5 \%$. When excavating the strata, it is essential to pay attention to the effect of creep. The failure strain of deep Cretaceous and Jurassic rocks is between $1 \%$ and $2 \%$, and the breaking and sudden collapse of surrounding rocks should be prevented.

\section{Introduction}

The artificial freezing method freezes the water in unstable water-bearing strata using artificial refrigeration, which can increase the strength and stability of the strata and isolate the interaction between groundwater and the construction operating surface. This is a special construction technology that enables safe and smooth evacuation for groundwater engineering under the protection of the frozen wall. This method has been used extensively because of its good waterproof performance. Frozen soil mechanics has been a discipline since the publication of the first paper on frozen soil mechanics in the USSR in the 1930s [1-4]. In 1955, the freezing method was introduced into China and applied to the construction of the Kailuan coal mine shaft. It was used extensively in the construction of new wells in the central and eastern regions of China in the 1980s. Considerable experience was gained in artificial freezing engineering in the third and fourth series of topsoil strata in the central and eastern regions, and numerous studies were carried out on the physical and mechanical performance of the artificial frozen soil [5-7]. In the 2000s, the freezing method was gradually extended to the construction of new wells in the western region and the reinforcement of the holes of subway shields and subway connection channels in the eastern coastal area. Research on the mechanical performance of the artificial frozen soil has since been conducted nationwide [8-14]. The freezing method works similarly whether it is 
applied to new well construction or subway construction. However, the application of the freezing method, for the purpose of reinforcement in different regions of China, raises the issue that strata conditions vary greatly from region to region. New well construction in the central and eastern regions mainly involves deep topsoil, while, in the northwestern region, it involves deep Cretaceous and Jurassic rock strata. Work on the eastern coastal subway involves shallow coastal topsoil. China has conducted intensive research on the physical and mechanical performance of the artificial frozen soil in the topsoil strata in the central and eastern regions. Less research has been conducted, however, on the physical and mechanical performance of the primary frozen strata in the eastern coastal portion of the northwestern region. Most of the methods of freezing design used in this region are the same as those used in the central and eastern regions. Because of significant differences in the low-temperature physical and mechanical performance of frozen rocks and soil in different regions [15-19], a good grasp of the physical and mechanical performance of frozen rocks and soil in a specific region is important to ensure the correctness of the freezing design scheme and ensuring the safety and stability of the frozen wall. In this study, representative rock and soil masses in the eastern coastal region, central region, and western region were selected for comparison. Based on the result of tests of low-temperature physical and mechanical performance, a reference guide for the selection of freezing parameters for various regions in China was developed.

\section{Test Plan}

2.1. Sample Sources. Samples were obtained from shallow coastal topsoil in the eastern coastal city of Fuzhou, representative deep topsoil in the central Huainan mining area, and deep cretaceous and Jurassic rock strata in the Dongsheng mining area in western Inner Mongolia. The samples were numbered D1-D9. Basic information about the condition of each one is provided in Table 1.

2.2. Test and Methodology. The types of physical and mechanical performance tests conducted are described as follows:

(1) The physical performance tests performed were tests of the water content; density; specific heat; thermal conductivity at normal temperature and at $-10^{\circ} \mathrm{C}$, freezing temperature; and frost heave ratio test at $-10^{\circ} \mathrm{C}$. The tests were performed in accordance with the national "Standards for Soil Test Methods" (GB/ T50123-2019) and the coal industry's "Physical and Mechanical Performances of Artificial Frozen Soil Test” (MT/T593-2011).

(2) The mechanical performance test performed was a uniaxial compressive strength test conducted under various temperature conditions, in accordance with the coal industry standard "Physical and Mechanical Performances of Artificial Frozen Soil Test” (MT/ T593-2011). Three samples from each stratum were processed to produce cylinders $50 \mathrm{~mm}$ in diameter and $100 \mathrm{~mm}$ in height. For samples of mucky soil and medium coarse sand, samples were prepared by remolded at reasonable water contents, densities, and other parameter levels determined from the physical performance tests on each soil layer. Samples were cured for $48 \mathrm{~h}$ at temperatures of $-5^{\circ} \mathrm{C}$, $-10^{\circ} \mathrm{C}$, and $-15^{\circ} \mathrm{C}$ and then subjected to uniaxial compressive strength testing using a WDT-100 frozen soil testing machine at a strain rate of $1.0 \%$ / min. The test procedure ensured that the sample axis coincided with the loading axis of the testing machine to avoid eccentric loading. Measurements of the force acting on the sample and the deformation of the sample were collected in real time. If the difference between the maximum or minimum and the median uniaxial compressive strength of three samples at each temperature level in each group exceeded $15 \%$ of the median, the results for this group of samples were judged to be too variable and to warrant resampling and retested. Because the rock strata in the D6-D9 group exhibited a certain selfstability under normal temperature conditions, the uniaxial compressive strength of the samples in this group was also tested under normal temperature conditions. The uniaxial compressive strength and elastic modulus are calculated from the test measurements, and the average values for three samples were taken as the final results for each group.

The uniaxial compressive strength of frozen rocks and soil $(\sigma)$ can be calculated as follows:

$$
\sigma=\frac{F_{\max }}{A}
$$

where $F_{\max }$ is the maximum measured test force, $\mathrm{N}$, and $A$ is the cross-sectional area of the calibrated sample, $\mathrm{mm}^{2}$.

The elastic modulus of frozen rock and soil $(E)$ can be calculated as follows:

$$
E=\frac{\sigma / 2}{\varepsilon_{1 / 2}},
$$

where $\varepsilon_{1 / 2}$ is the sample strain corresponding to half of the uniaxial compressive strength (\%).

\section{Results of Physical Performance Tests}

The physical performance parameter values of the different rock and soil strata were determined from the test results and are summarized in Tables 2 and 3. The following conclusions were drawn from the test results:

(1) The water content of the topsoil strata is high $(>18 \%)$, while that of the rock strata is low $(<10 \%)$. Since these rock strata were more recently formed and are poorly cemented, they will have exhibited argillation, disintegration, and other phenomena in a short time after being in contact with water. Because of the low water content of the rocks, the freezing 
TABLE 1: Basic condition of rock strata samples.

\begin{tabular}{|c|c|c|c|c|}
\hline Region & Strata & Number & Name of strata & Depth $(\mathrm{m})$ \\
\hline \multirow{2}{*}{ Eastern } & \multirow{2}{*}{ Shallow coastal topsoil } & D1 & Mucky soil & $13.90-20.50$ \\
\hline & & D2 & Medium coarse sand & $22.08-29.30$ \\
\hline \multirow{3}{*}{ Central } & \multirow{3}{*}{ Deep topsoil } & D3 & Clay & $252.6-264.0$ \\
\hline & & D4 & Calcareous clay & $297.0-315.0$ \\
\hline & & D5 & Sandy clay & $353.3-381.1$ \\
\hline \multirow{4}{*}{ Western } & \multirow{2}{*}{ Cretaceous rock strata } & D6 & Sandy mudstone & $222.3-236.9$ \\
\hline & & D7 & Gritstone & $263.7-286.5$ \\
\hline & \multirow{2}{*}{ Jurassic rock strata } & D8 & Gritstone & $378.6-393.8$ \\
\hline & & D9 & Mudstone & $521.4-532.6$ \\
\hline
\end{tabular}

TABLE 2: Physical performance of different rock and soil strata determined from tests.

\begin{tabular}{|c|c|c|c|c|c|c|}
\hline Number & Strata & $\begin{array}{c}\text { Water content } \\
(\%)\end{array}$ & $\begin{array}{l}\text { Density } \\
\left(\mathrm{g} / \mathrm{cm}^{3}\right)\end{array}$ & $\begin{array}{l}\text { Specific heat } \\
(\mathrm{J} /(\mathrm{g} \cdot \mathrm{K}))\end{array}$ & $\begin{array}{l}\text { Freezing temperature } \\
\left({ }^{\circ} \mathrm{C}\right)\end{array}$ & Frost heave ratio (\%) \\
\hline D1 & Mucky soil & 44.04 & 1.71 & 1.05 & -1.80 & 1.54 \\
\hline D2 & $\begin{array}{c}\text { Medium coarse } \\
\text { sand }\end{array}$ & 18.87 & 1.95 & 1.71 & -1.20 & 1.23 \\
\hline D3 & Clay & 22.17 & 2.07 & 1.42 & -1.80 & 1.23 \\
\hline D4 & Calcareous clay & 22.59 & 2.04 & 1.43 & -2.00 & 1.32 \\
\hline D5 & Sandy clay & 21.72 & 2.13 & 1.41 & -1.50 & 1.19 \\
\hline D6 & Sandy mudstone & 8.84 & 2.35 & 1.13 & -2.10 & 0.56 \\
\hline D7 & Gritstone & 6.57 & 2.43 & 1.05 & -1.40 & 0.23 \\
\hline D8 & Gritstone & 7.88 & 2.36 & 0.93 & -1.60 & 0.13 \\
\hline D9 & Mudstone & 5.28 & 2.39 & 0.98 & -2.60 & 0.00 \\
\hline
\end{tabular}

TABLe 3: Change in thermal conductivity of different rock and soil strata at normal and low temperatures.

\begin{tabular}{lcccc}
\hline Number & Strata & Normal temperature $(\mathrm{W} /(\mathrm{m} \cdot \mathrm{K}))$ & $-10^{\circ} \mathrm{C}(\mathrm{W} /(\mathrm{m} \cdot \mathrm{K}))$ & 1.86 \\
\hline D1 & Mucky soil & 1.42 & 2.93 & 30.99 \\
D2 & Mediumcrease $(\%)$ \\
D3 & Clay & 2.14 & 2.00 & 36.92 \\
D4 & Calcareous clay & 1.59 & 1.90 & 25.79 \\
D5 & Sandy clay & 1.49 & 2.10 & 27.47 \\
D6 & Sandy mudstone & 1.58 & 3.21 & 32.91 \\
D7 & Gritstone & 2.68 & 3.49 & 19.78 \\
D8 & Gritstone & 2.99 & 3.50 & 16.72 \\
D9 & Mudstone & 2.87 & 3.35 & 21.95 \\
\hline
\end{tabular}

temperature of the rock strata is also lower than that of the topsoil strata. The freezing temperature of the rock strata is in the range of -1.4 to $-2.6^{\circ} \mathrm{C}$.

(2) The topsoil strata have a frost heave ratio greater than $1 \%$ at $-10^{\circ} \mathrm{C}$, and it is necessary to take into account the effect of frost heave on the surroundings. The frost heave ratio of the sandy mudstone of the D6 group was $0.56 \%$. Except for that, all the other three groups of rock strata have small frost-heaving ratios. The frost heave ratio of the Jurassic rocks in group D9 was 0 , which indicates that not all of the rock and soil mass can undergo frost heaving when the temperature is below zero. If there is not enough water to participate in freezing of the rock and soil mass, the particles and ice inside will follow the thermal expansion and contraction mechanism, and thus the rock and soil mass will frost shrink rather than freeze.
(3) The thermal conductivity of the strata other than the sandy soil strata was approximately $2.0 \mathrm{~W} /(\mathrm{m} \cdot \mathrm{K})$, while the thermal conductivity of the rock strata was greater than $3.0 \mathrm{~W} /(\mathrm{m} \cdot \mathrm{K})$ at low temperatures. As the temperature drops from normal to $-10^{\circ} \mathrm{C}$, the thermal conductivity of different rock and soil mass increases significantly. In the increase of the topsoil, the increase in the thermal conductivity can be approximately $30 \%$, and the thermal conductivity of the rock strata can increase by approximately $20 \%$. The temperature field of the rock strata and the sandy soil strata in the topsoil develops relatively quickly at low temperatures, which is conducive to freezing. In contrast, in the remaining topsoil strata, especially the mucky soil and calcareous clay, which have relatively low thermal conductivities, the freezing temperature field develops relatively slowly at low temperatures. 


\section{Results of Low-Temperature Mechanical Performance Tests}

4.1. Mechanical Performance. Analyses of the uniaxial compressive strength test results showed how the two strength parameters considered, the uniaxial compressive strength and elastic modulus, varied with temperature for different rock and soil strata, as shown in Figures 1 and 2 . The percentage changes in the strength parameter values of the sample for different temperature changes were calculated and are summarized in Table 4. The conclusions from these results are as follows:

(1) At low temperatures, the strength of topsoil strata was significantly improved over that under normal temperatures, and the strength gradually increased as the curing temperature decreased. When the temperature decreased from $-5^{\circ} \mathrm{C}$ to $-10^{\circ} \mathrm{C}$, the strength increase was between 28.42 and $76.74 \%$, and when the temperature decreased from $-10^{\circ} \mathrm{C}$ to $-15^{\circ} \mathrm{C}$, the strength increase was between 26.33 and $54.20 \%$, which indicates that the rate of strength improvement decreased with decreasing temperature. In the cases of the mucky soil (group D1) and calcareous clay (group D4), when the temperature decreased from $-5^{\circ} \mathrm{C}$ to $-10^{\circ} \mathrm{C}$, the strength increased by $68.16 \%$ and $76.74 \%$, respectively, whereas when the temperature decreased from $-10^{\circ} \mathrm{C}$ to $-15^{\circ} \mathrm{C}$, the strength increased by only $45.85 \%$ and $41.12 \%$, respectively.

(2) The strength of the rock strata also increased with decreasing curing temperature, but the range of increase was different for the rock strata than for the topsoil strata. For the two groups D6 and D9, which were from the mudstone rock strata, the strength increases were only $5.51 \%$ and 5.79 , respectively, when the temperature decreased from normal to $-5^{\circ} \mathrm{C}$. In contrast, for the two groups D7 and D8, which were from the sandstone rock strata, when the temperature decreased from normal to $-5^{\circ} \mathrm{C}$, the strength increased by $66.98 \%$ and $24.00 \%$, respectively, which are considerably greater increases than those of the mudstone rock strata groups. When the temperature dropped from $-5^{\circ} \mathrm{C}$ to $-10^{\circ} \mathrm{C}$, the strength increase of the mudstone rock strata was greater, and the sandy mudstones (D6 group) were $51.97 \%$. In contrast, the strength increases of the sandstone rock strata (D7 and D8) declined by $26.63 \%$ and $23.76 \%$, respectively. When the temperature decreased from $-10^{\circ} \mathrm{C}$ to $-15^{\circ} \mathrm{C}$, the strength increase of all of the remaining groups declined, except for the coarse sandstone in group D7, whose strength increase was greater than when the temperature changed from $-5^{\circ} \mathrm{C}$ to $-10^{\circ} \mathrm{C}$.

(3) The strengths of topsoil strata groups with different properties varied greatly. At the same low temperature, the strength of the sandy soil strata was the highest, followed by that of the cohesive soil strata in the mucky soil and the calcareous clay. For example, at $-10^{\circ} \mathrm{C}$, the strength of the mucky soil in the D1 group and the calcareous clay in the D4 group was only approximately $3 \mathrm{MPa}$, while that of the medium coarse sand in the D2 group was $4.51 \mathrm{MPa}$, a difference of more than $50 \%$. The strength of the frozen wall and the waterproof requirements both must be taken into consideration in the freezing design. The strength of the Jurassic strata was slightly higher than that of the Cretaceous strata, both of which were more than $5 \mathrm{MPa}$ under normal temperature conditions. The strength of the mudstone in group D9 was as high as $14.68 \mathrm{MPa}$. When the temperature was $-5^{\circ} \mathrm{C}$, the strength of the rock strata in each group was greater than $7.8 \mathrm{MPa}$; when the temperature dropped to $-10^{\circ} \mathrm{C}$, the strength in each group was greater than 11.2 $\mathrm{MPa}$. Because of the high strengths of the Cretaceous and Jurassic strata, the waterproof requirements of the frozen wall should be the primary concern in the freezing design.

(4) The trends in the elastic modulus of frozen rocks and soil with changes in temperature were consistent with those for the uniaxial compressive strength: the elastic moduli of both the frozen rock and soil groups increased with decreasing curing temperature. When the curing temperature decreased from the normal temperature to $-10^{\circ} \mathrm{C}$, the increases in the elastic moduli were relatively large, whereas when the curing temperature was less than $-10^{\circ} \mathrm{C}$, the increases in the elastic moduli were small. The elastic moduli of the topsoil strata were between $80.16 \mathrm{MPa}$ and $153.34 \mathrm{MPa}$ at $-10^{\circ} \mathrm{C}$; the elastic modulus of the rock strata was considerably larger and can reach more than $300 \mathrm{MPa}$ at normal temperature.

As shown in Figures 1 and 2, the uniaxial compressive strength and elastic modulus of the topsoil strata increased almost linearly with decreasing temperature. While the rock strata exhibited the same trend of increases in strength parameters with decreasing temperature, the parameter values did not increase linearly with change in temperature and actually varied greatly mainly because of the presence which is mainly caused by the existence of many fissure surfaces in the rocks and the differences in the strength parameters values of the different samples.

The variations in the uniaxial compressive strength and elastic modulus with a temperature of the topsoil strata can be expressed by the following linear equations: $\sigma=a+b T$ and $E=c+d T$, where $a, b, c$, and $d$ are coefficients whose values are determined by testing and $T$ is the temperature, ${ }^{\circ} \mathrm{C}$. The fitted equations are shown in Table 5, which also shows that the correlation coefficient for each is greater than 0.995 .

4.2. Comparative Analysis of Failure Characteristics. The failure stress and failure strain are two important failure parameters of the uniaxial compressive strength test for frozen rocks and soil. The failure stress is the peak value of 


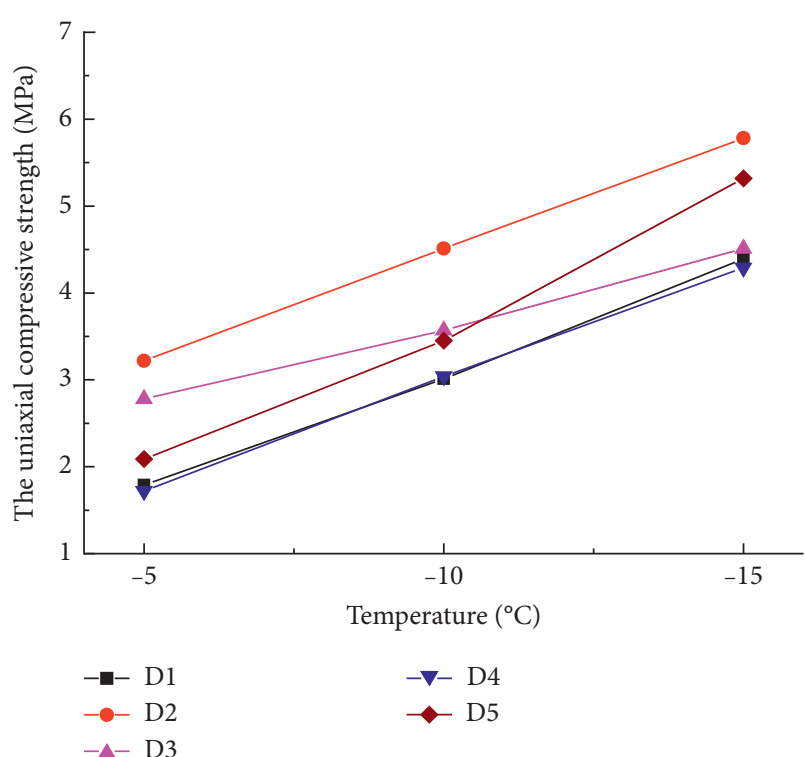

(a)

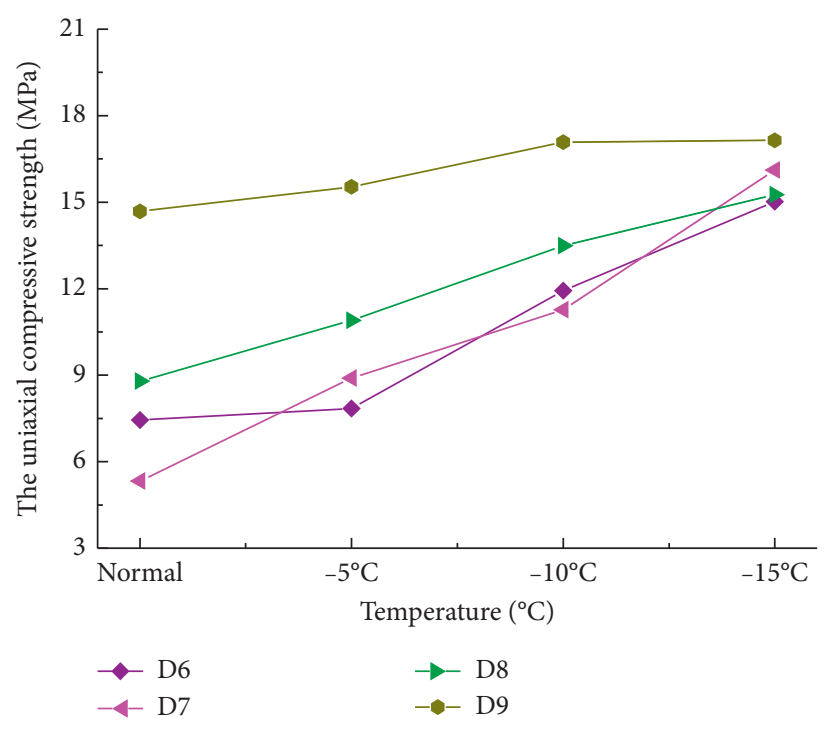

(b)

Figure 1: Uniaxial compressive strengths of different rock and soil strata versus temperature. (a) Topsoil strata. (b) Rock strata.

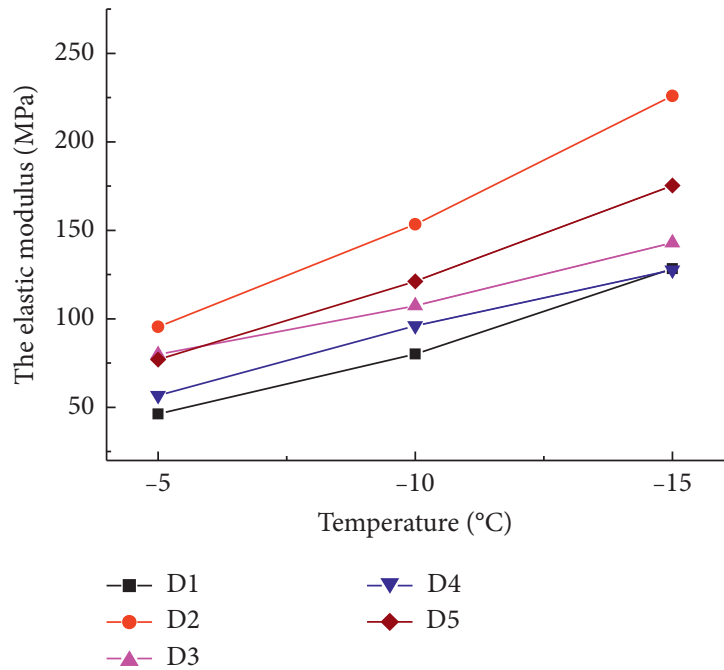

(a)

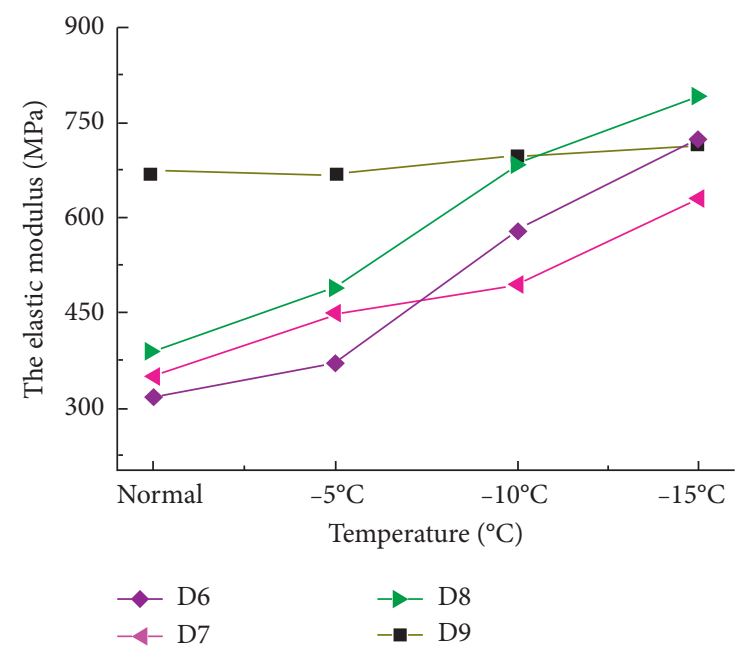

(b)

FIGURE 2: Elastic moduli of different rock and soil strata versus temperature. (a) Topsoil strata. (b) Rock strata.

stress in the stress-strain correlation curve when the frozen soil is damaged, that is, when the corresponding strain of the sample's uniaxial compressive strength is the failure strain. However, some frozen rocks and soil samples exhibit a plastic stage after loading, in which the samples are not damaged or show extreme values of stress even when the strain reaches $30 \%$ or higher. When this occurs, $20 \%$ of the axial strain in the uniaxial compressive strength test is generally taken as the failure strain, and the corresponding stress is taken as the failure stress. Therefore, in this test, when the applied force reaches its peak value, loading continues until one of the following three conditions exists: the strain increases by $5 \%$, the force decreases by $15 \%$ from the peak value, or the sample axial strain reaches $20 \%$ even though the force is still increasing. If any of these occurs, the test is stopped. These protocols were used to obtain the stress-strain correlation curves for the frozen rocks and soil in the different strata.

4.2.1. Comparison of Failure Stress and Failure Strain of Frozen Rocks and Soil in Different Strata. The stress-strain correlation curves of the second sample in each group tested at $-10^{\circ} \mathrm{C}$ were selected for comparative analysis, and the 
TABLE 4: Percentage increases in sample strength parameters for different temperature changes.

\begin{tabular}{|c|c|c|c|c|c|c|c|}
\hline \multirow{2}{*}{ Number } & \multirow{2}{*}{ Strata } & \multicolumn{3}{|c|}{$\begin{array}{l}\text { Uniaxial compressive strength percentage increase } \\
(\%)\end{array}$} & \multicolumn{3}{|c|}{ Elastic modulus percentage increase (\%) } \\
\hline & & Normal temperature to $-5^{\circ} \mathrm{C}$ & $\begin{array}{c}-5^{\circ} \mathrm{C} \text { to } \\
-10^{\circ} \mathrm{C}\end{array}$ & $\begin{array}{c}-10^{\circ} \mathrm{C} \text { to } \\
-15^{\circ} \mathrm{C}\end{array}$ & Normal temperature to $-5^{\circ} \mathrm{C}$ & $\begin{array}{c}-5^{\circ} \mathrm{C} \text { to } \\
-10^{\circ} \mathrm{C}\end{array}$ & $\begin{array}{l}-10^{\circ} \mathrm{C} \text { to } \\
-15^{\circ} \mathrm{C}\end{array}$ \\
\hline D1 & Mucky soil & - & 68.16 & 45.85 & - & 73.32 & 60.02 \\
\hline D2 & $\begin{array}{l}\text { Medium coarse } \\
\text { sand }\end{array}$ & - & 40.06 & 28.16 & - & 60.62 & 47.30 \\
\hline D3 & Clay & - & 28.42 & 26.33 & - & 34.71 & 32.93 \\
\hline D4 & Calcareous clay & - & 76.74 & 41.12 & - & 69.21 & 32.81 \\
\hline D5 & Sandy clay & - & 65.07 & 54.20 & - & 57.40 & 44.64 \\
\hline D6 & $\begin{array}{l}\text { Sandy } \\
\text { mudstone }\end{array}$ & 5.51 & 51.97 & 25.90 & 17.46 & 57.00 & 24.26 \\
\hline D7 & Gritstone & 66.98 & 26.63 & 42.95 & 27.18 & 10.79 & 27.31 \\
\hline D8 & Gritstone & 24.00 & 23.76 & 13.12 & 26.39 & 39.54 & 15.78 \\
\hline D9 & Mudstone & 5.79 & 9.98 & 0.35 & -0.95 & 4.50 & 2.00 \\
\hline
\end{tabular}

TABle 5: Fitted curves for uniaxial compressive strength and elastic modulus versus temperature for different geotechnical samples.

\begin{tabular}{|c|c|c|c|c|c|}
\hline Position & Strata & $\begin{array}{l}\text { Fitting equation of uniaxial } \\
\text { compressive strength }\end{array}$ & $\begin{array}{c}\text { Correlation } \\
\text { coefficient }\end{array}$ & $\begin{array}{l}\text { Fitting equation } \\
\text { of elastic modulus }\end{array}$ & Correlation coefficient \\
\hline D1 & Mucky soil & $\sigma=0.48-0.26 T$ & 0.99984 & $E=2.87-8.20 T$ & 0.99504 \\
\hline D2 & $\begin{array}{l}\text { Medium coarse } \\
\text { sand }\end{array}$ & $\sigma=1.98-0.26 T$ & 0.99877 & $E=27.83-13.04 T$ & 0.99790 \\
\hline D3 & Clay & $\sigma=1.89-0.17 T$ & 0.99875 & $E=46.97-6.31 T$ & 0.99753 \\
\hline D4 & Calcareous clay & $\sigma=0.45-0.26 T$ & 0.99990 & $E=22.66-7.08 T$ & 0.99800 \\
\hline D5 & Sandy clay & $\sigma=0.39-0.32 T$ & 0.99587 & $E=26.20-9.83 T$ & 0.99831 \\
\hline
\end{tabular}

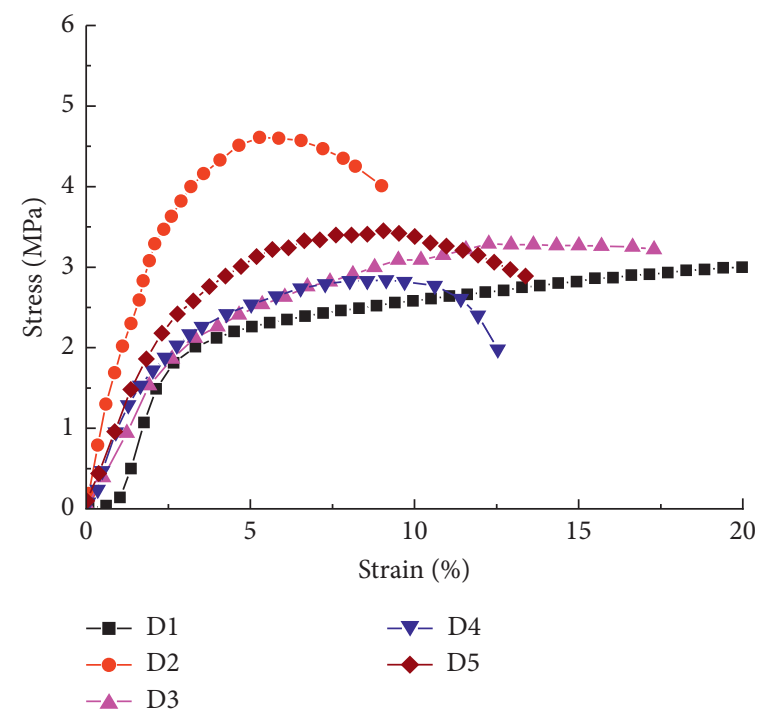

(a)

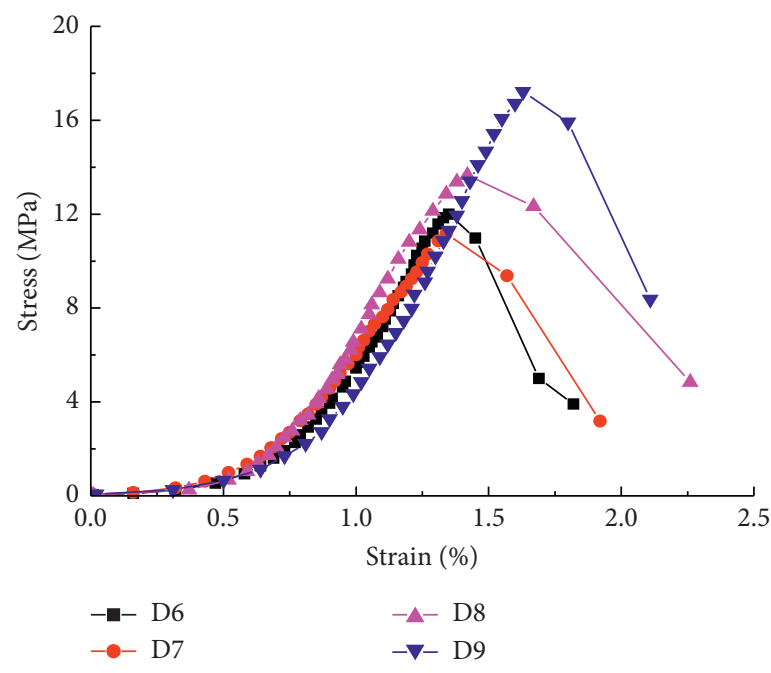

(b)

Figure 3: Stress-strain correlation curve of different rock and soil samples at $-10^{\circ} \mathrm{C}$ (second sample in each group). (a) Topsoil strata. (b) Rock strata.

failure stress and failure strain of each sample were calculated, as shown in Figure 3 and Table 6. The samples of mucky soil in group D1 and clay in group D3 exhibited compression failure, and the stress-strain behavior was of the elastic-strain-hardening type. The stress in the mucky soil in group D1 increased steadily up to $20 \%$ strain. The strain corresponding to the peak stress of the clay in group D3 was $12.26 \%$. The strain then continued to increase by $5 \%$, while the strength only decreased by $0.2 \mathrm{MPa}$. The medium coarse sand in group D2 and the sandy clay in group D5 also exhibited compression failure, but their stress-strain behavior was of the elastic-strain-softening type. The failure 
TABLe 6: Parameter comparison of failure stress and failure strain of different rock and soil strata at $-10^{\circ} \mathrm{C}$.

\begin{tabular}{lccc}
\hline Number & Strata & Failure stress (MPa) & Failure strain (\%) \\
\hline D1 & Mucky soil & 3.00 & 20.00 \\
D2 & Medium coarse sand & 4.61 & 5.28 \\
D3 & Clay & 3.29 & 12.26 \\
D4 & Calcareous clay & 2.84 & 9.14 \\
D5 & Sandy clay & 3.45 & 9.05 \\
D6 & Sandy mudstone & 12.00 & 1.35 \\
D7 & Gritstone & 11.18 & 1.34 \\
D8 & Gritstone & 13.66 & 1.42 \\
D9 & Mudstone & 17.22 & 1.63 \\
\hline
\end{tabular}

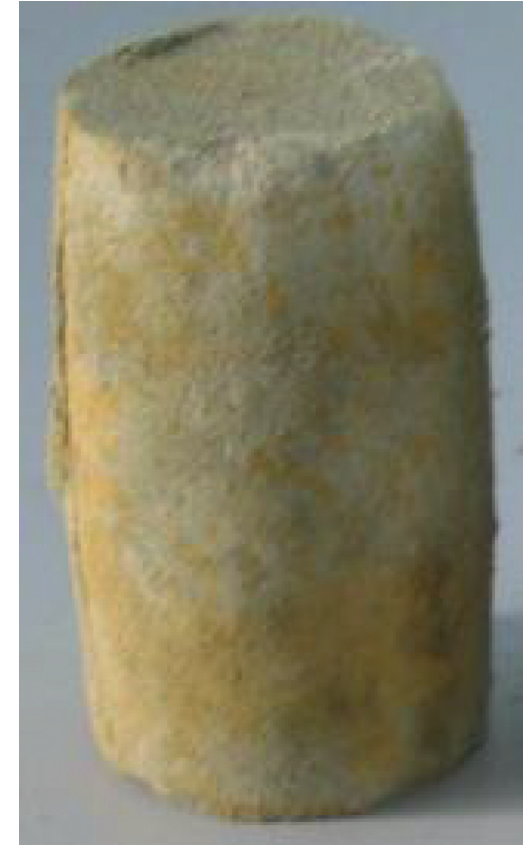

(a)

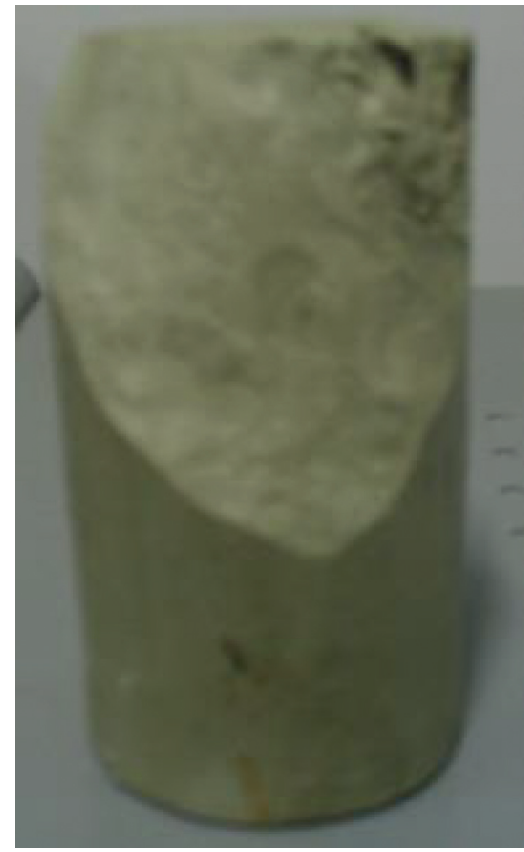

(b)

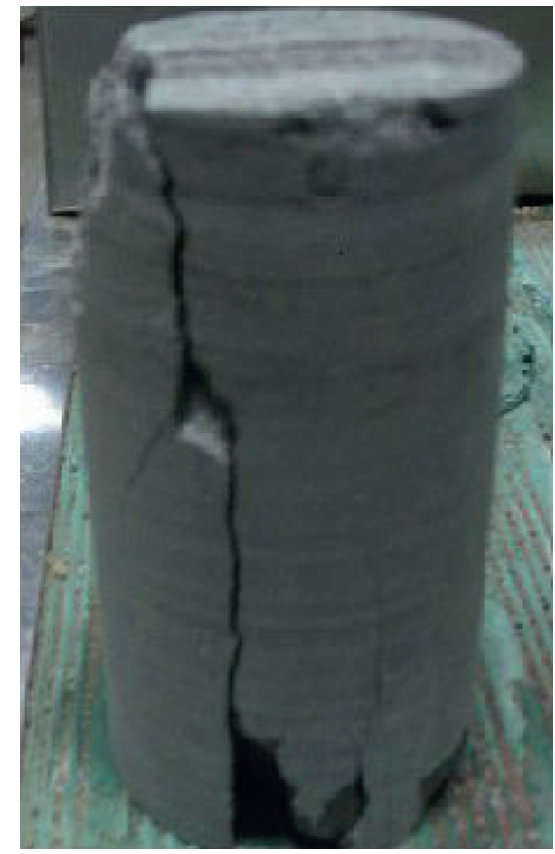

(c)

FIGURE 4: Rock and soil failure modes. (a) Compression failure. (b) Single inclined plane shear failure. (c) Splitting failure.

TABLE 7: Comparison of average failure strains of samples for each group for different temperature conditions.

\begin{tabular}{|c|c|c|c|c|}
\hline \multirow{2}{*}{ Number } & \multirow{2}{*}{ Strata } & \multicolumn{3}{|c|}{ Average failure strain (\%) } \\
\hline & & $-5^{\circ} \mathrm{C}$ & $-10^{\circ} \mathrm{C}$ & $-15^{\circ} \mathrm{C}$ \\
\hline D1 & Mucky soil & 20.00 & 20.00 & 20.00 \\
\hline $\mathrm{D} 2$ & Medium coarse sand & 6.63 & 5.28 & 4.98 \\
\hline D3 & Clay & 13.42 & 12.26 & 10.69 \\
\hline $\mathrm{D} 4$ & Calcareous clay & 10.43 & 9.06 & 7.22 \\
\hline D5 & Sandy clay & 10.22 & 9.15 & 7.85 \\
\hline D6 & Sandy mudstone & 1.42 & 1.33 & 1.28 \\
\hline D7 & Gritstone & 1.45 & 1.31 & 1.4 \\
\hline D8 & Gritstone & 1.33 & 1.45 & 1.36 \\
\hline D9 & Mudstone & 1.88 & 1.66 & 1.53 \\
\hline
\end{tabular}

strains of the medium coarse sand in group D2 and the sandy clay in group D5 were 5.28\% and 9.05\%, respectively, indicating that a higher sand content corresponded to a smaller failure strain. Although the stress-strain behavior of the calcareous clay in group D4 was also of the elastic-strainsoftening type, after the sample reached the peak stress, the strain remained steady at only approximately 3\% until monopitched shear failure occurred because of the weak structural plane. The freezing strength of the rock strata was higher than that of the topsoil strata, both of which exhibited split failure. The stress-strain behaviors of both were the compaction-elasticity-softening type, manifested in three 
stages: from pore fissure compaction-elastic deformation to microelastic fissure development to fracture, with failure strains in the range of $1 \%$ to $2 \%$. Figures $4(a)-4(c)$ illustrate the compression failure of the medium coarse sand in the D2 group, the shear failure of the single inclined plane of the calcareous clay in the D4 group, and the shape of the coarse sandstones in the D8 group after splitting failure.

\subsubsection{Effects of Temperature on Failure Strain of Frozen Rocks} and Soil. The failure strains of three samples in each group under different temperature conditions were averaged and compared. It was concluded that, for the topsoil strata, the temperature had no effect on the average failure strain of the D1 mucky soil. This was mainly because of the large pore size of the sample, which increases the stress in the sample during compression. The average failure strain remained at $20 \%$ under different temperature conditions. However, the temperature had a greater influence on the average failure strain of the remaining four groups of samples. The average failure strain decreased with decreasing temperature, the plasticity of the strata samples of the elastic-strain-hardening type declines, while the brittleness of these samples increases. Nevertheless, all of the failure strains were greater than $5 \%$ at $-10^{\circ} \mathrm{C}$. These results indicate, that during excavation, the strata should be supported in a timely manner to control the creep deformation of the strata. For the rock strata, the average failure strain, which was between $1 \%$ and $2 \%$, was slightly affected by the temperature. This indicates that, during excavation, temporary support to the strata should be provided to prevent the sudden collapse of surrounding rocks. The average failure strains of the samples in each group at different temperatures conditions are shown in Table 7.

\section{Conclusions}

By means of laboratory tests of frozen rock and soil samples from the eastern, central, and northwestern regions of China, the differences in the physical and mechanical performance of the different rock and soil strata in the different regions at low temperatures were examined. The main conclusions are as follows:

(1) The thermal conductivities of the different strata were found to differ. The thermal conductivities of the mucky soil and calcareous clay in the topsoil strata were relatively low, and the development rate of the frozen wall temperature field was relatively slow, whereas the thermal conductivity of the rock strata was high, and the frozen wall temperature field developed relatively quickly, which is conducive to freezing. When calculating the thickness of the frozen wall, the effect of the freezing temperature of rock and soil mass should be taken into consideration.

(2) At low temperatures, the temperature has a greater impact on the uniaxial compressive strengths of different rock and soil strata, and the strength increase with decreasing temperature occurs primarily when the normal temperature drops to $-10^{\circ} \mathrm{C}$. For the topsoil strata, the uniaxial compressive strength and elastic modulus increased almost linearly with decreasing temperature. At the same temperature, the strength of the sandy soil strata was the highest, followed by the cohesive soil strata, the mucky soil, and the calcareous clay. The strength and waterproof requirements of a frozen wall should be taken into account in the freezing design. For the rock strata, because of its high strength, the design of the frozen wall should mainly consider its waterproof requirements.

(3) At low temperatures, the topsoil samples subjected to uniaxial compression failed predominantly in compression, whereas the calcareous clay was affected by the presence of a weak structural plane and exhibited monopitched shear failure. The rock exhibited splitting failure. The stress-strain behavior of the mucky soil and cohesive soil strata was mostly the elastic-strain-hardening type, while that of the calcareous clay and sandy soil strata was of the elastic-strain-softening type. The stress-strain behavior of the Cretaceous and Jurassic rock strata was of the compaction-elastic-softening type.

(4) For the topsoil strata, the average failure strain was greater than $5 \%$ at $-10^{\circ} \mathrm{C}$. For on-site excavation, early the strata should be supported in a timely manner to control the creep deformation of the strata. For the Cretaceous and Jurassic rock strata, the average failure strain was in the range of $1 \%$ to $2 \%$. Temporary support of these strata should be performed in time to prevent surrounding rocks from suddenly breaking and collapsing during onsite excavation.

Since the physical and mechanical properties of frozen rock and soil in different soil layers in different regions of China are very different, the samples tested in this study were obtained from the deep topsoil in the central region, the Cretaceous and Jurassic rocks strata in the western region, and the shallow coastal topsoil in the eastern region, where artificial freezing is widely used. The results of this study can provide guidance for the characterization of low-temperature physical and mechanical properties of soils in other regions. However, specific low-temperature physical and mechanical property tests are still needed to accurately determine the low-temperature physical and mechanical properties of soils in other regions.

\section{Data Availability}

The data used to support the findings of this study are included within the article.

\section{Conflicts of Interest}

The authors declare that they have no conflicts of interest regarding the publication of this paper. 


\section{Acknowledgments}

This research was supported by the Key Laboratory Open Subject Fund of Fujian University of Underground Engineering (KF-T18014), the Outstanding Young Scientific Research Talents Cultivation Program of Fujian University (GY-Z17070), the Research Development Fund of Fujian Institute of Engineering (GY-Z17158), the Fujian Provincial Natural Science Foundation Projects (2017Y4001), and the projects of Fuzhou Science and Technology Bureau (2017-G59 and 2018-G-77).

\section{References}

[1] H. A. Tsytovich, Mechanics of Frozen Soil, Science Press, Beijing, China, 1985.

[2] X. S. Chen, "Study on frozen soil mechanics-one of the important field of rock and soil mechanics in 21st century," Journal of China Coal Society, vol. 23, pp. 55-59, 1998.

[3] J. L. Qi and W. Ma, "State-of-art of research on mechanical properties of frozen soils," Rock and Soil Mechanics, vol. 31, pp. 137-147, 2010.

[4] W. Ma and D. Y. Wang, "Studies on frozen soil mechanics in China in past 50 years and their prospect," Chinese Journal of Geotechnical Engineering, vol. 34, pp. 625-640, 2011.

[5] Lanzhou Institute of Glaciology and Cryopedology and Chinese Academy of Sciences, Engineering Behaviour of Frozen Wall in Artificial Freezing Sinking, Lanzhou University Press, Lanzhou, China, 1988.

[6] J. Z. Qi, D. S. Chu, and Y. Z. Han, "Experimental study on physical and mechanical properties of artificial frozen soil of Qidong mine," Journal of Huainan Institute of Technology, vol. 19 , pp. 54-58, 1999.

[7] C. X. Wang, "Test and study on physical mechanism performance of freezed silt soil," Coal Science and Technology, vol. 28, pp. 9-12, 2000.

[8] Y. Liu, R. H. Wang, and J. H. Chen, "Experiment study on physical mechanics performances of cretaceous system rock under minus temperature," Coal Engineering, vol. 43, pp. 90-92, 2011.

[9] F. M. Chen, J. H. Chen, and Y. Q. Qi, "Experimental study on physical and mechanical properties of red stratum under minus temperature," China Coal, vol. 37, pp. 48-51, 2011.

[10] B. Liu, Y. J. Ma, H. L. Sheng, H. L. Deng, Q. Han, and Y. J. Cao, "Experimental study on mechanical properties of cretaceous red sandstone under different freezing temperatures and confining pressures," Chinese Journal of Rock Mechanics and Engineering, vol. 39, pp. 455-466, 2019.

[11] Y. J. Shen, H. W. Yang, J. M. Xi, Y. Yang, Y. Z. Wang, and $\mathrm{X}$. Wei, "A novel shearing fracture morphology method to assess the influence of freeze-thaw actions on concrete-granite interface," Cold Regions Science and Technology, vol. 169, Article ID 102900, 2020.

[12] H. B. Cai, P. F. Li, and Z. F. Wu, "Model test of liquid nitrogen freezing-temperature field of improved plastic freezing pipe," Journal of Cold Regions Engineering, vol. 34, Article ID 04020001, 2020.

[13] Q. Yan, W. Wu, C. Zhang, S. Ma, and Y. Li, "Monitoring and evaluation of artificial ground freezing in metro tunnel construction-a case study," KSCE Journal of Civil Engineering, vol. 23, no. 5, pp. 2359-2370, 2019.

[14] Y. Tang and J. Li, "Experimental study on dynamic cumulative axial-strain performance of freezing-thawing saturated sandy silt," Cold Regions Science and Technology, vol. 155, pp. 100107, 2018.

[15] Y. J. Shen, Y. Z. Wang, X. Wei, H. L. Jia, and R. X. Yan, "Investigation on meso-debonding process of the sandstoneconcrete interface induced by freeze-thaw cycles using NMR technology," Construction and Building Materials, vol. 252, Article ID 118962, 2020.

[16] W. Ma and X. Chang, "Analyses of strength and deformation of an artificially frozen soil wall in underground engineering," Cold Regions Science and Technology, vol. 34, no. 1, pp. 11-17, 2002.

[17] X. Huang, D. Q. Li, and F. Ming, "Experimental study of the compressive and tensile strengths of artificial frozen soil," Journal of Glaciology and Geocryology, vol. 38, pp. 1346-1352, 2016.

[18] S. C. Liu, G. S. Li, B. Li, and M. Zhang, "Study on the mechanical properties of permafrost about Ningbo contact channel for underground tunnels," Bulletin of Science and Technology, vol. 35, pp. 120-123, 2019.

[19] Y. Shen, Y. Wang, Y. Yang, Q. Sun, T. Luo, and H. Zhang, "Influence of surface roughness and hydrophilicity on bonding strength of concrete-rock interface," Construction and Building Materials, vol. 213, pp. 156-166, 2019. 